\title{
Establishment of Shaped Charge Optimum Parameters for Small Scale Hydrodynamic Penetration
}

\author{
Khairul H. Kamarudin ${ }^{1}$, Ahmad Mujahid Ahmad Zaidi ${ }^{1}$, Shohaimi Abdullah ${ }^{1} \&$ Md Fuad Shah Koslan ${ }^{1}$ \\ ${ }^{1}$ Faculty of Engineering, National Defence University of Malaysia, Malaysia \\ Correspondence: Khairul H. Kamarudin, Faculty of Engineering, National Defence University of Malaysia, \\ 57000 Kuala Lumpur, Malaysia. Tel: 60-13-620-4605. E-mail: khairul.hasni@upnm.edu.my
}

Received: September 9, 2015

doi:10.5539/mas.v10n1p82

\author{
Accepted: September 25, 2015 Online Published: December 22, 2015 \\ URL: http://dx.doi.org/10.5539/mas.v10n1p82
}

\begin{abstract}
An investigation is intended to establish suitable parameters for a simple shaped charge mechanism (SCM) assembly that can be utilized for small scale hydrodynamics penetration test. Some basic features of the SCM parameters were based on previous researchers' findings. Three sets of tests were conducted to verify parameters such as cone liner angle and thickness, material of charge (explosive) casing and standoff distance (SoD). Single and welded stacks of mild steel plates and Aluminium blocks were used as targets. Two type of explosive were used, military grade plastic explosive (PE) or $\mathrm{C} 4$ and a commercial grade explosive, Emulex 700. A simple but effective compressing mechanism was developed to eliminate air pockets and maximised the explosive density. The SCM parameters were improved through series of tests and results have shown that hydrodynamic penetrations have taken place in every test conducted. Suitable small scale SCM parameters were successfully established which can be utilized for future study on hydrodynamics penetration.
\end{abstract}

Keywords: hydrodynamics penetration, shaped charge, charge casing, cone liner, standoff

\section{Introduction}

Shaped charge (SC) is an explosive mechanism used to penetrate thick targets such as an armoured plate, stone boulder or for digging into soil. The term shaped charge was taken from the shape formed at the explosive end. These shapes can be made by fitting a concaved shaped metal liner which will provide density to the hydrodynamic jet produced by the blast for improved penetration (Poole, 2005). The liner shape is usually hemisphere, conical or trumpet (Walters \& Zukas, 1989). The most commonly used are copper cone liner but other liner materials include zirconium, aluminium, steel and depleted uranium (Bourne, Cowan, \& Curtis, 2001; Doig, 1998; Held, 2001). When a SCM is detonated, the metal liner is compressed and squeezed forward, forming a hypervelocity jet of up to $12 \mathrm{~km} / \mathrm{s}$ (Poole, 2005). Simplified shaped charge events are shown in Figure 1. The SCM as shown in Figure 1(a), when initiated produces detonation wave that traverses the charge and expand the casing (b). The liner begins to 'collapse' followed by a significant acceleration that initiates the stretching jet. The liner continues to collapse with increasing jet acceleration (c) and finally stretches in a sword-like feature (d).

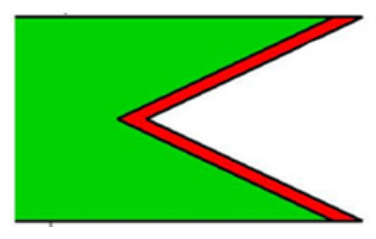

(a)

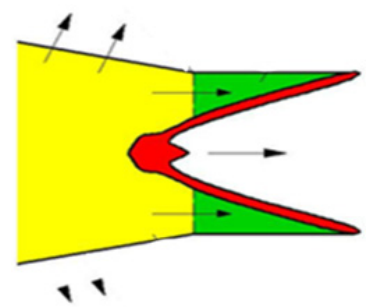

(b)

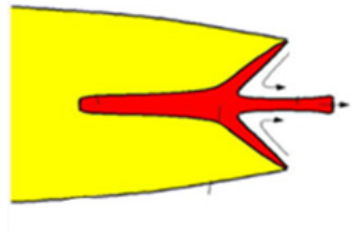

(c)

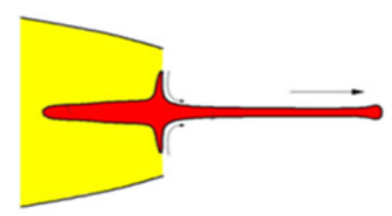

(d)

Figure 1. A sequence of events in shaped-charge jet formation (GlobalSecurity.org, 2011) 
The metal liner collapse and formation of jet is called a shaped charge Monroe-effect. It is capable of creating a long, slender, almost perfectly-axisymmetric cavity in the target (Poole, 2005), penetrating an armoured plate equal to $150-250 \%$ of the warhead diameter. The penetration on metal target also has proven to exhibit both hydrodynamic and plastic deformation (GlobalSecurity.org, 2011) behaviour.

\subsection{Basic Shaped Charge Configuration}

A basic shaped charge mechanism as shown in Figure 2 consist of charge casing, cone liner, explosive and booster-detonator.

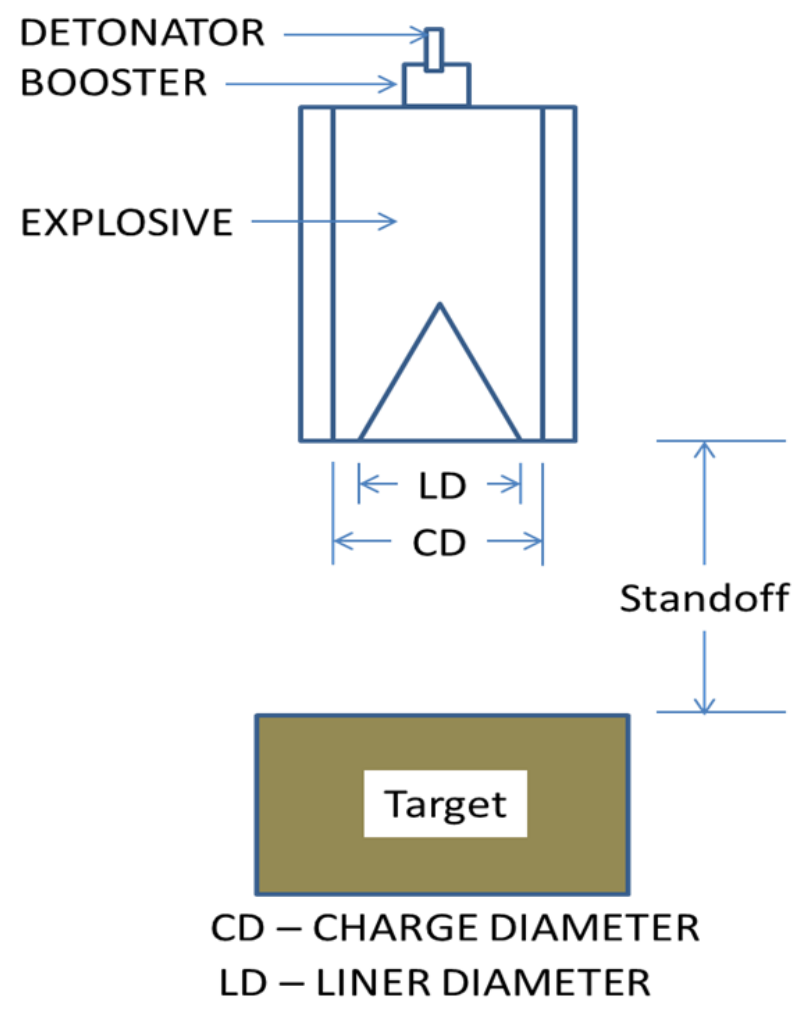

Figure 2. Basic shaped charge mechanism (Walters, 2007)

\subsection{Cone Liner}

In 1988, a shaped charge experiment using high-performance explosive in cylindrical case with a conical cavity lined with thin aluminium has succeeded in achieving a hypervelocity impact of $11 \mathrm{~km} / \mathrm{s}$ (Kibe \& Matsushima, 2002). Another test has shown a high precision and relatively consistent result from shaped charge using a relatively pure copper cone liner (Baker, Pham, Madse, Poulos, \& Fuchs, 2013). It was assumed earlier that the jet tip velocity is relatively insensitive to the liner manufacturing methods, grain size, and strength. However, an experiment in 2007 has proven otherwise (Ouye, Boeka, \& Hancock, 2007). Previous experiments also demonstrate better penetration results using copper cone liner with cone angle of $42^{\circ}$ (Bolstad, Mandell, \& Mendius, 1992).

\subsection{Standoff Distance (SoD)}

Standoff distance (SoD) is a distance between the front of the liner and the target (Poole, 2005). It is observed that a longer jet leads to deeper penetration, and so the appropriate stand-off must be estimated to maximise the jet length. (Poole, 2005) A moderate SoD is suggested to be 3 x CD (Saran, Ayisit, \& Yavuz, 2013). The relationship between SoD and penetration depth is shown in Figure 3. 


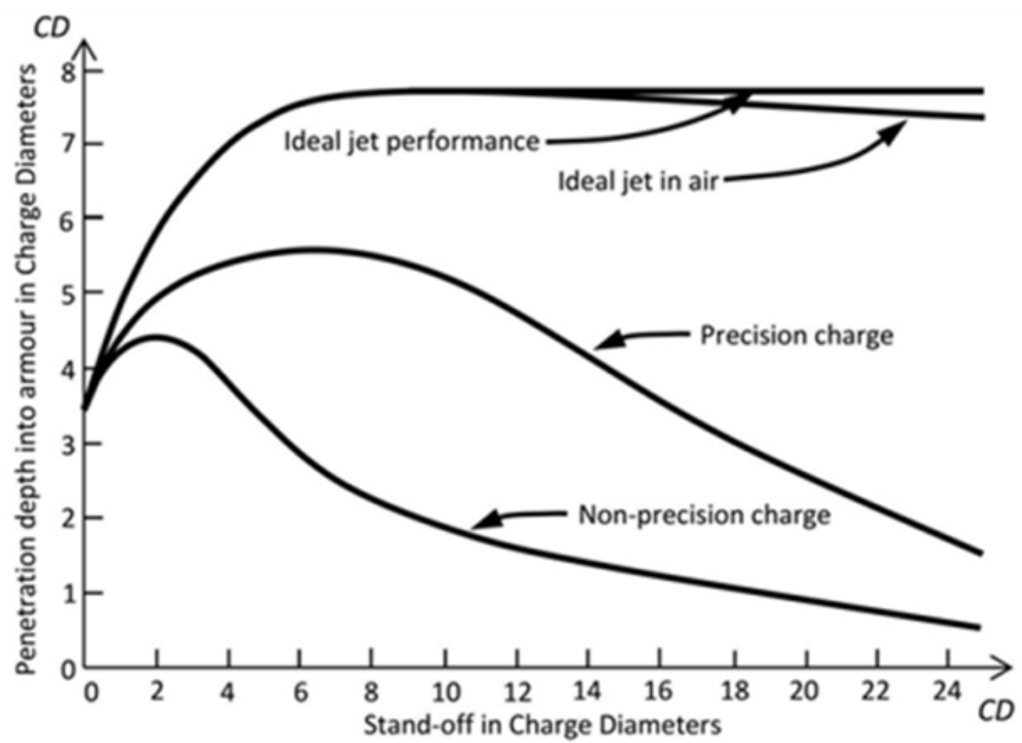

Figure 3. The relationship between standoff height and penetration depth (Johnsson, Vretblad, \& Sivertun, 2012 )

\subsection{Explosive Material}

The most common explosive used in high performance anti-armor warheads is HMX (Octogen: Cyclotetramethylene tetranitramine (Cooper, 1996; Bolton, Simke, Pagoria, \& Matzger, 2012); VoD =9,400 m/s, Density $=1.91 \mathrm{~g} / \mathrm{cm} 3$ ). HMX is normally compounded with a few percent of some type of plastic binder, such as in the polymer-bonded explosive (PBX) LX-14, or with another less-sensitive explosive, such as TNT (Trinitrotoluene (Cooper, 1996; Bolton et al., 2012) ); $\mathrm{VoD}=6,900 \mathrm{~m} / \mathrm{s}$, Density $=1.60 \mathrm{~g} / \mathrm{cm} 3$ ), with which it forms Octol (globalsecurity.org, 2011). Other common high-performance explosives are RDX-based compositions (Cyclotrimethylenetrinitramine (Cooper, 1996; Bolton et al., 2012); VoD = 8,750, Density $=1.76$ $\mathrm{g} / \mathrm{cm} 3$ ). Some explosives incorporate powdered aluminium to increase their blast and detonation temperature, but this addition generally results in decreased performance of the shaped charge. There has been research into using the very high-performance but sensitive explosive CL-20 (Hexanitrohexaazaisowurtzitane (Cooper, 1996; Bolton et al., 2012); $\mathrm{VoD}=9,500 \mathrm{~m} / \mathrm{s}$, Density $=2.04 \mathrm{~g} / \mathrm{cm} 3$ ) in shaped-charge warheads, but, at present, due to its sensitivity, this has been in the form of the PBX composite LX-19 (CL-20 and Estane binder) (globalsecurity.org, 2011). Explosives used in these test are Plastics explosive, $\mathrm{C} 4(\mathrm{VoD}=8092 \mathrm{~m} / \mathrm{s}$ at density $=$ 1.72-1.75 g/cm3) (U.S. Department of the Army Headquarters, 1990), and a commercial explosive, EMULEX 700 (Tenaga Kimia Sendirian Berhad, 2014), $(\mathrm{VoD}=5000-5500 \mathrm{~m} / \mathrm{s}$ at density $=1.15-1.20 \mathrm{~g} / \mathrm{cc})$.

\section{Method}

The tests were conducted in two phases. Phase one is a preliminary experiment to test the parameters of the designed SC mechanism assembly and phase two is to test the performance of the improved SC mechanism assembly.

\subsection{Phase 1: Preliminary Test on Basic Shaped Charge Mechanism Parameters}

A shaped charge mechanism (SCM) assembly was constructed as shown in Figure 4 with target plate located below the SCM. 


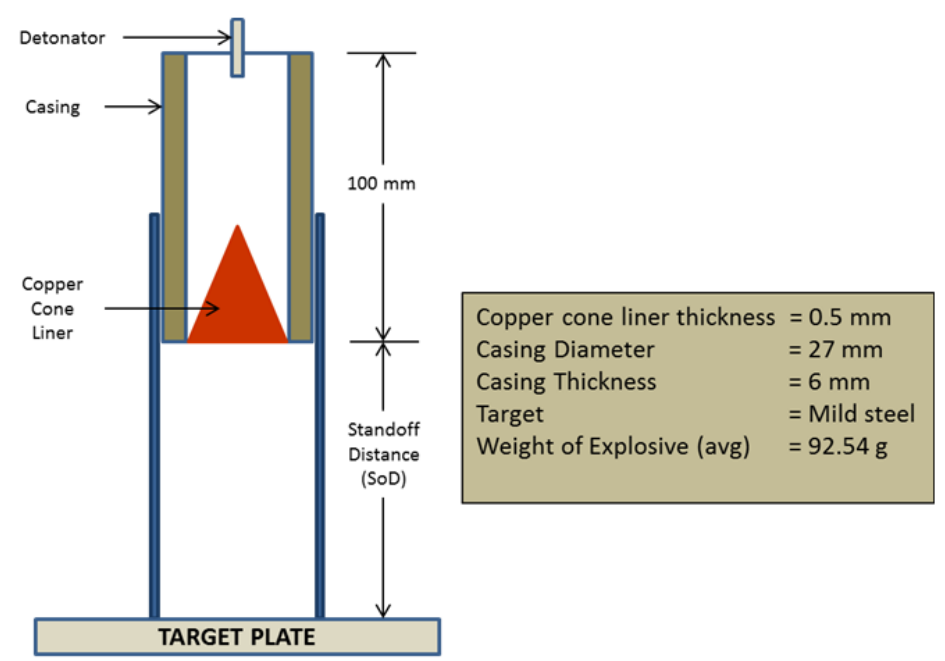

Figure 4. A basic shaped charge mechanism assembly

A variable casing material, standoff height, cone thickness and cone angle were used and tested. Copper Cone liners of thickness $0.5 \mathrm{~mm}$ were fabricated as shown in Figure 5. Two types of explosives were used, i.e. a miltary grade PE no. 4 and commercial explosive, EMULEX 700. Electric detonators were used to initiate the blast.
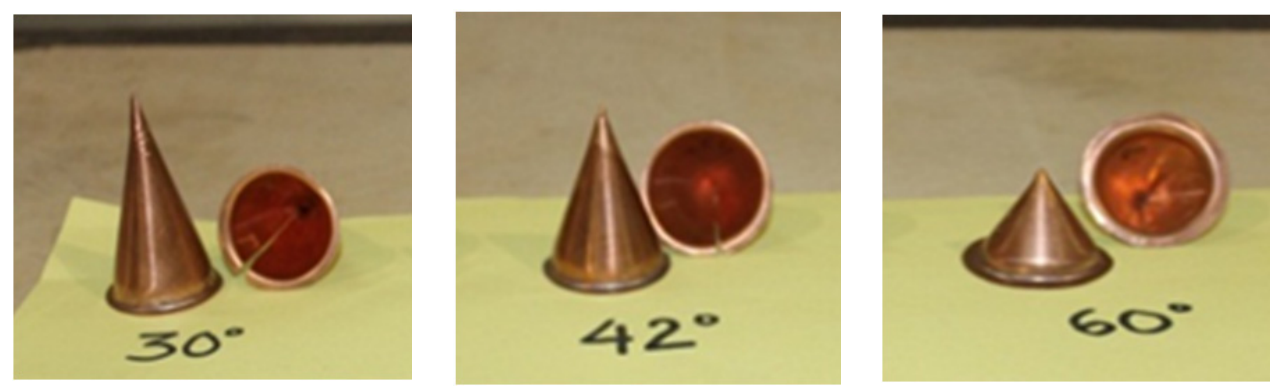

Figure 5. Cone Liners; $30^{\circ}, 42^{\circ}$ and $60^{\circ}$

The shaped charge mechanism and target material setup for the preliminary blast test is shown in Figure 6. PE was used for these penetration tests using $9 \mathrm{~mm}$ mild steel plate as target.

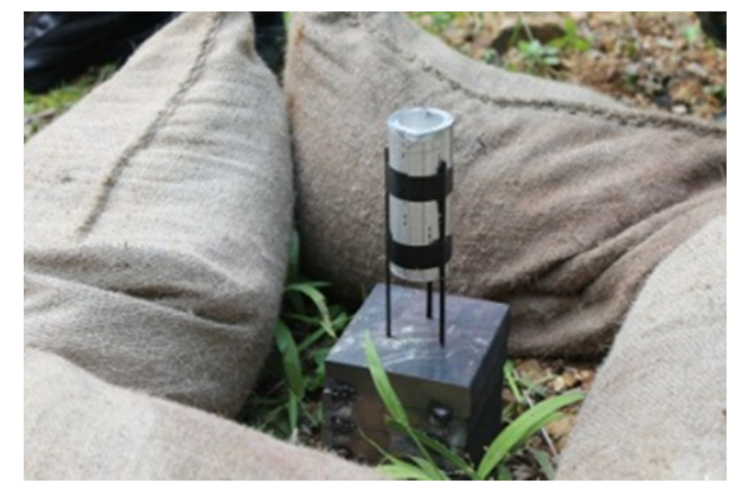

Figure 6. Shaped charge mechanism and target material setup 


\subsection{Phase 2: Penetration Test on Improved Shaped Charge Mechanism}

The preliminary tests were observed as discussed in in paragraph 4 after which an improved design and fabrication of the SCM was developed.

\subsubsection{Improved Shaped Charge Mechanism (SCM) Assembly}

Based on the results and observations from the preliminary tests, an improved design and parameters of the shaped charge mechanism (SCM) assembly is as shown in Figure 7. A Cone Angle of $42^{\circ}$ and $1.0 \mathrm{~mm}$ thickness is selected as it is proven to produce better penetration results. Another cone with $0.5 \mathrm{~mm}$ thickness was also fabricated to confirm the preliminary test results. A Mild Steel, Aluminium and PVC casing was fabricated for testing using military grade explosive PE and a commercial grade explosive, EMULEX. The stand-off height of 2.0 and 2.5 casing diameter was selected for the subsequent tests.
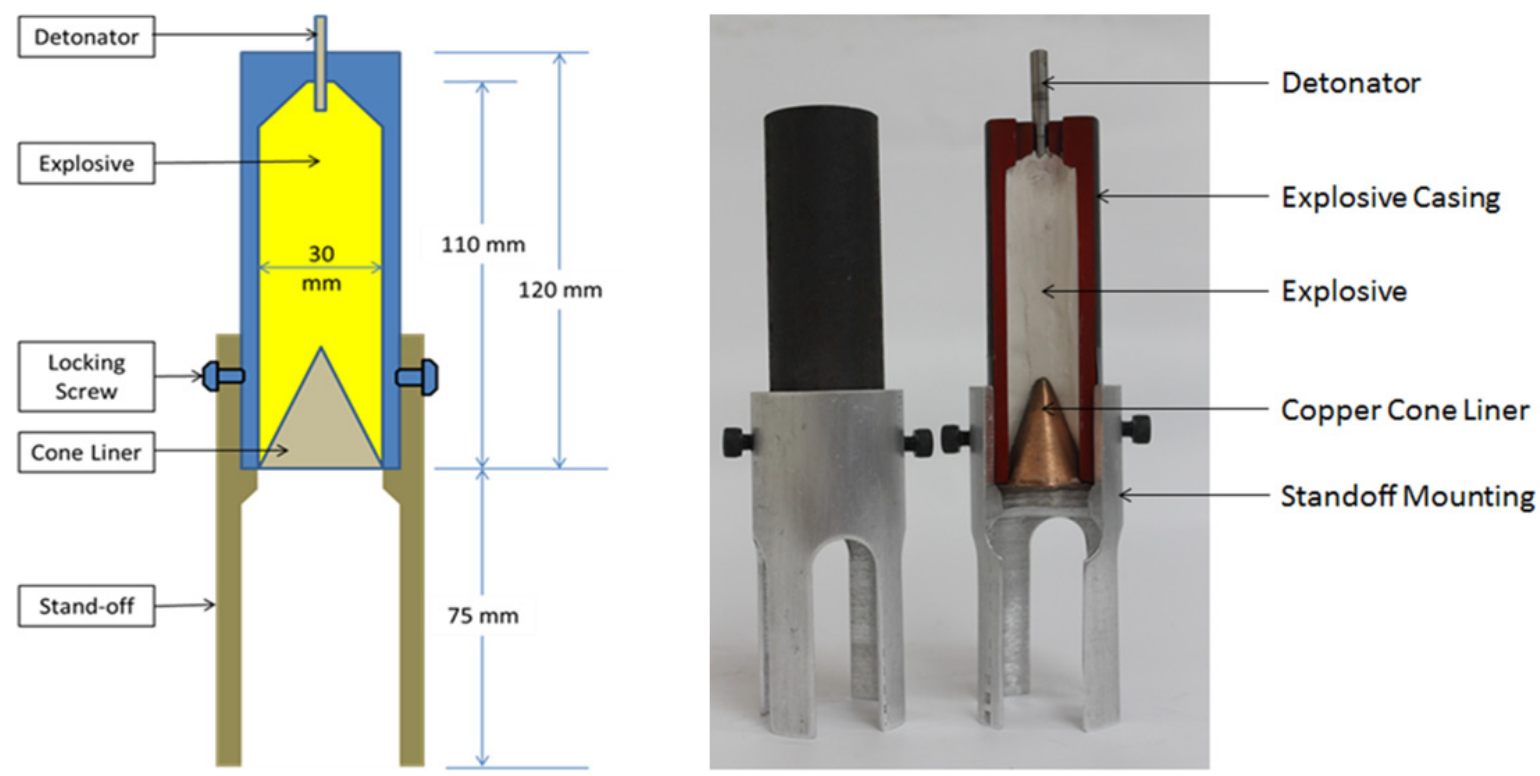

Figure 7. Improved Shaped Charge Mechanism Assembly

To cone was fabricated from a copper sheet by hand and joined using copper brazing followed by a heat treatment to cure the cold working and brazing effect during its fabrication as shown in Figure 8a, 8b, 8c and 8d.

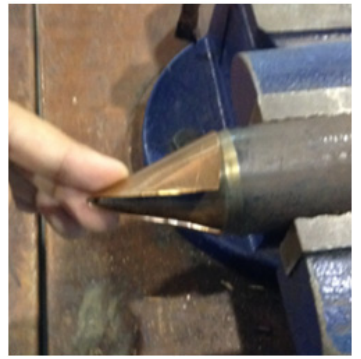

a. Shaping

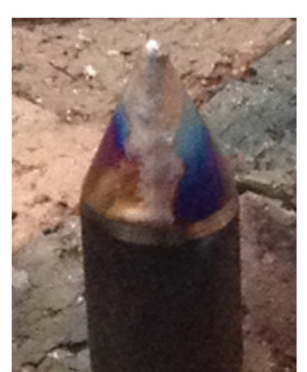

b. Brazing

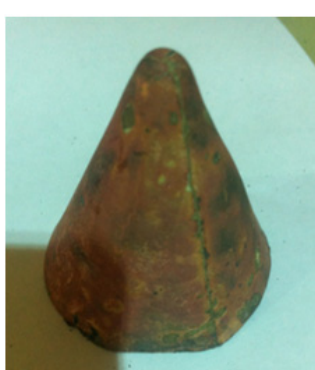

c. Heat Treated

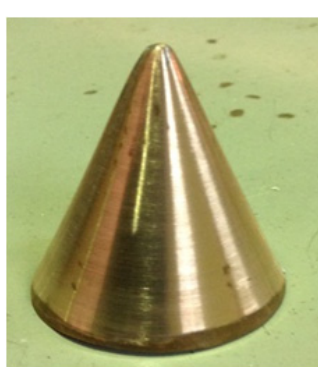

d. Polished

Figure 8. Copper Cone Fabrication Process

\subsubsection{Preparation of Plastic Explosive}

The explosive materials used must be adequately compressed to minimize air pockets inside the shaped charge and to get maximum explosive density thus maximizing the blast pressure results. Therefore, a simple but effective explosive compressing rig was fabricated as shown in Figure 9a and $9 \mathrm{~b}$. 


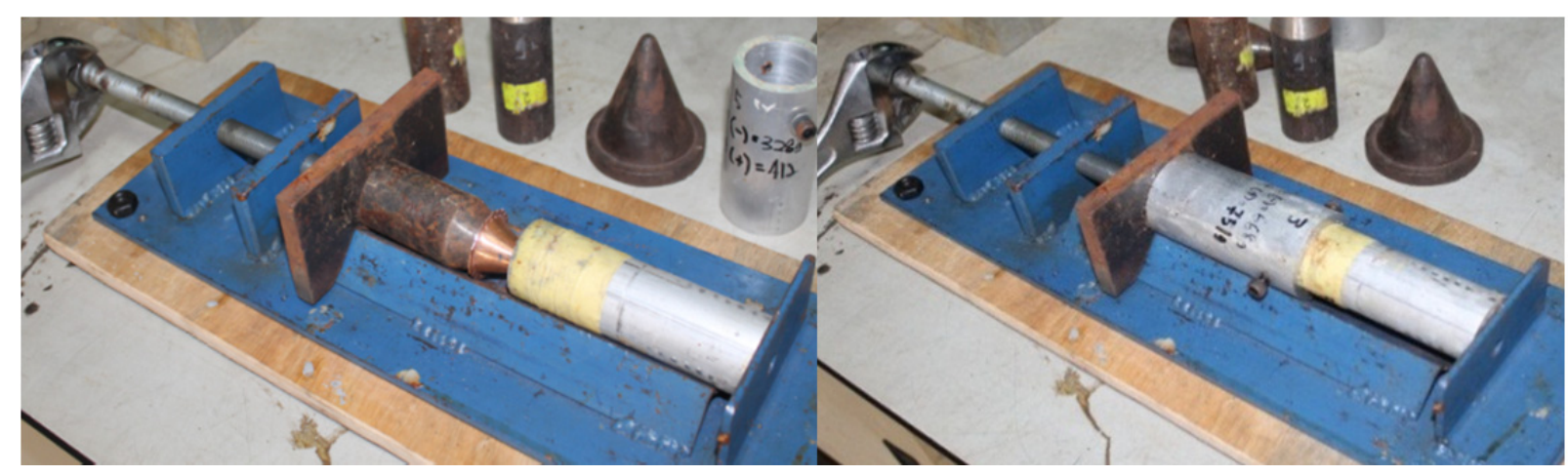

a. Compressing explosive into the casing

b. Compressing and locking the standoff

Figure 9. Compressing Mechanism Assembly

\subsubsection{Improved Shaped Charge Mechanism (SCM) Penetration Test Setup}

Eight blast tests were conducted using the improved SCM using military grade explosive PE and commercial grade explosive EMULEX. The first sets of tests were conducted using Military Grade Explosive PE on Mild Steel Target with Variable Casing Materials and Cone Thickness. The second sets of tests were conducted using Commercial Grade Explosive EMULEX on Aluminium target using Cone angle $42^{\circ}$ and Cone thickness $1.0 \mathrm{~mm}$, with Variable Casing material and Standoff Height. Examples of test setup are shown in Figure 10a, 10b and 10c below.

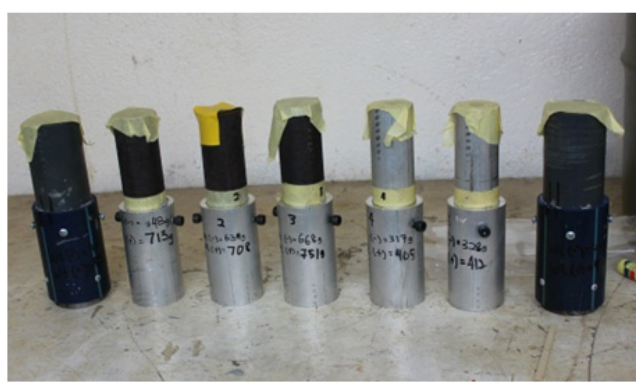

a. PVC, mild steel and Aluminum Casing

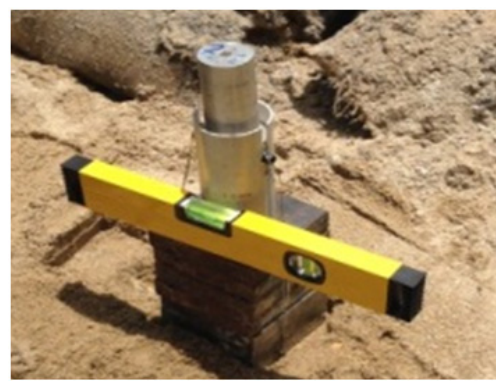

b. Mild steel target

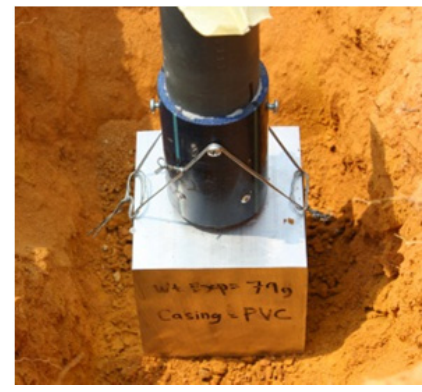

c. Aluminium Target

Figure 10. Test Setup for the Improved Shaped Charge Mechanism

\section{Results}

\subsection{Preliminary Test Results}

The preliminary test results for penetration using variable cone angles and casing materials are shown in Table 1 .

Table 1. Preliminary Penetration Test results Using Military Grade Explosive PE on Mild Steel Target with Variable Type of Casing, Standoff Height, Cone Angle and Cone Thickness

\begin{tabular}{cccccc}
\hline Test No & Casing Material & Standoff Height & Cone Angle & Cone Thickness & Result \\
\hline & & & & & \\
1 & Mild Steel & $75 \mathrm{~mm}$ & $30^{\circ}$ & $0.5 \mathrm{~mm}$ & \\
\hline
\end{tabular}




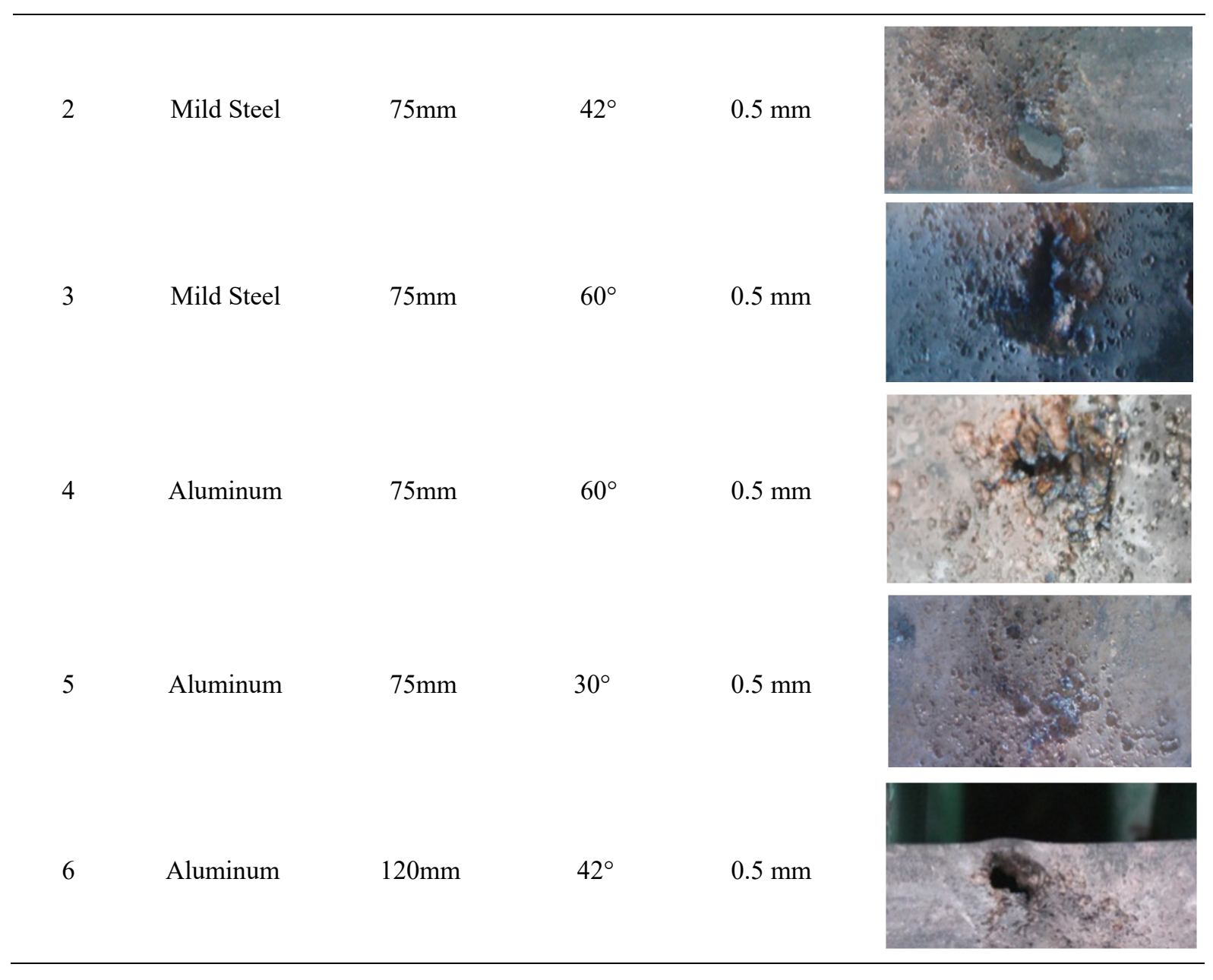

\subsection{Improved Shaped Charge Mechanism Penetration Test Results}

Eight blast tests were conducted using the improved SCM using military grade explosive PE and commercial grade explosive EMULEX. Results are tabulated and illustrated in Table 2 and Table 3 respectively.

Table 2. Penetration Test using Military Grade Explosive PE on Mild Steel Target Using Variable Casing Materials and Cone Thickness. (Fixed parameters: cone angle $42^{\circ}$, stand-off height $75 \mathrm{~mm}$ )

\begin{tabular}{|c|c|c|c|c|}
\hline Test No & Casing Material & Cone Thickness & Result & Penetration \\
\hline 1 & Mild Steel & $1.0 \mathrm{~mm}$ & & $93 \mathrm{~mm}$ \\
\hline 2 & Mild Steel & $0.5 \mathrm{~mm}$ & & $38 \mathrm{~mm}$ \\
\hline
\end{tabular}




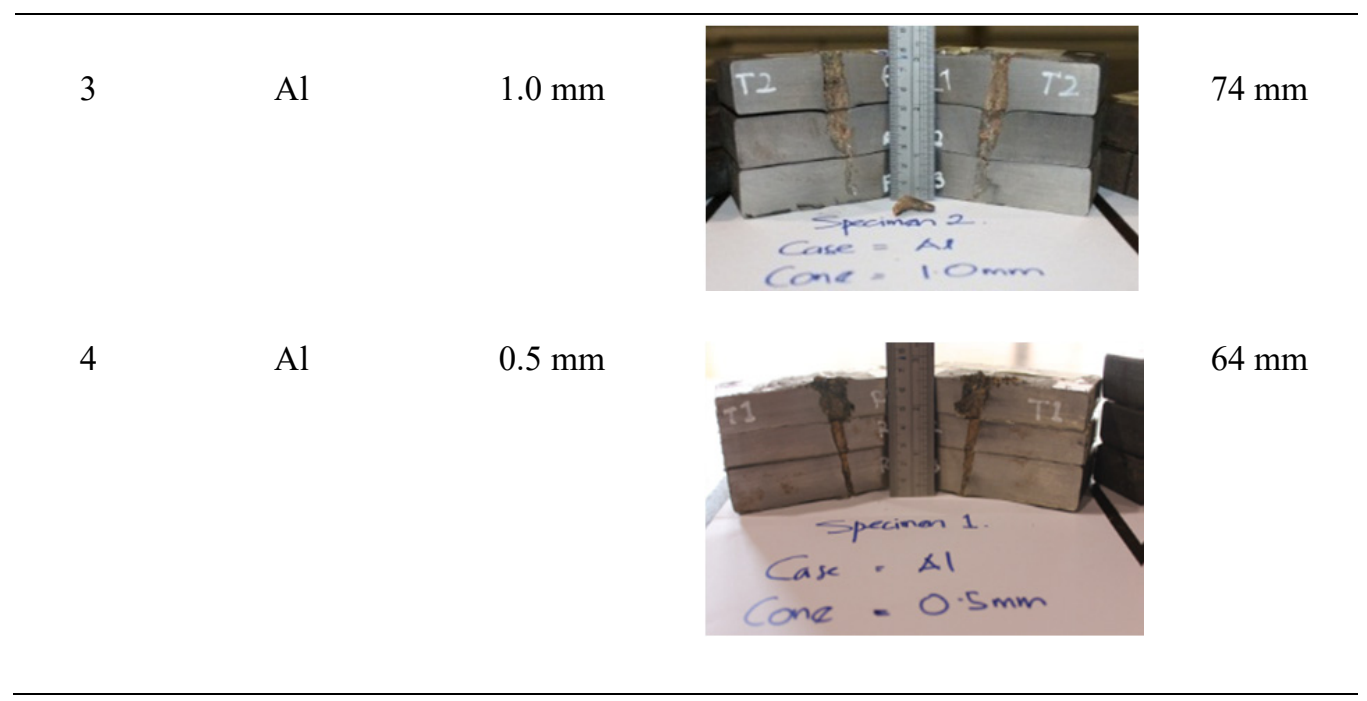

Table 3. Penetration Test using Commercial Grade Explosive EMULEX on Aluminium Target, Using Variable Casing material and Standoff Height. (Fixed Parameters: Cone angle $42^{\circ}$ and Cone thickness $1.0 \mathrm{~mm}$ )

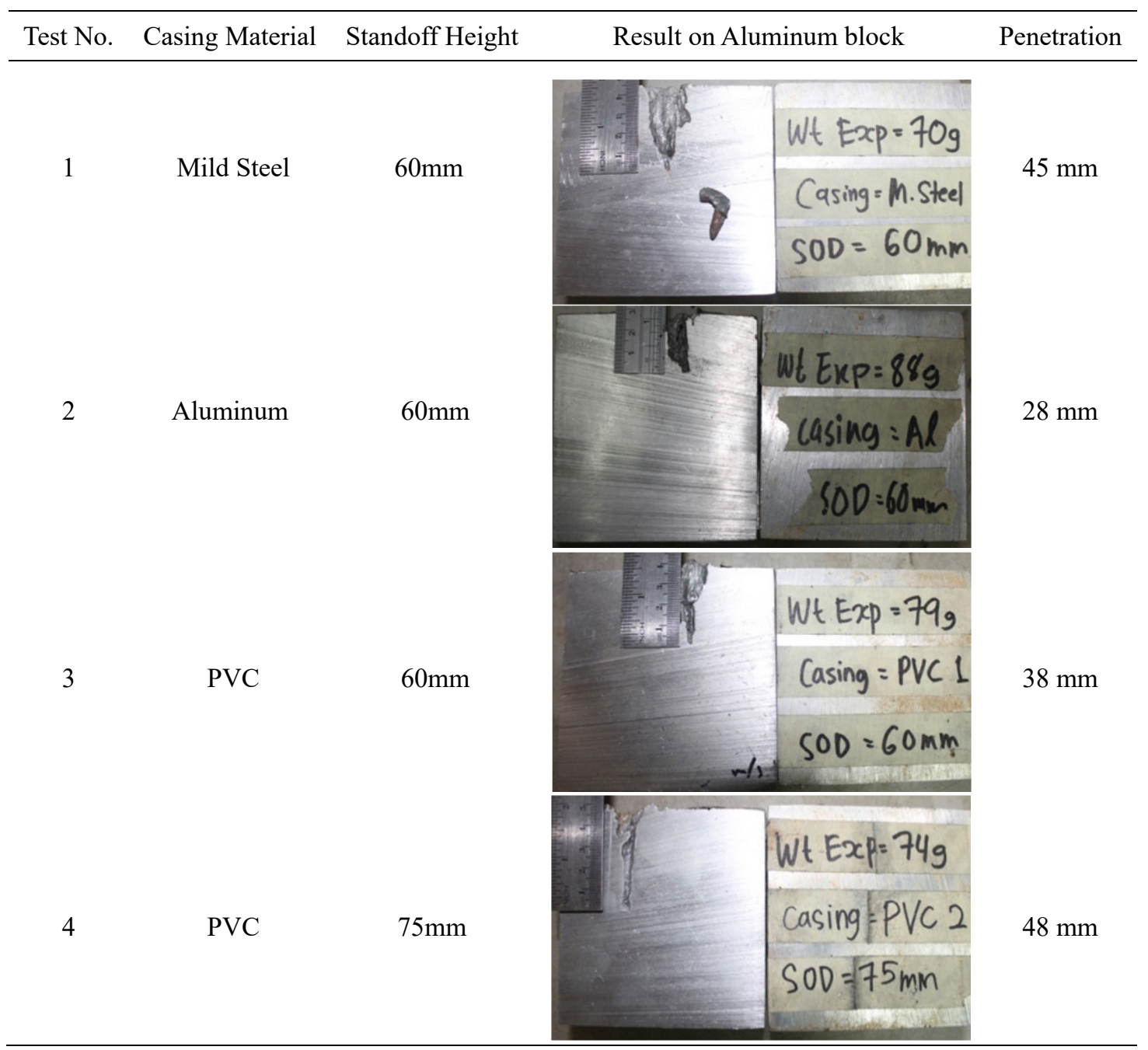

\section{Discussion}

A SCM was fabricated with fixed casing diameter of $30 \mathrm{~mm}$. The preliminary test were conducted using military 
grade explosive PE and by fixing the cone thickness at $0.5 \mathrm{~mm}$. Results from the preliminary experiment shows better penetration for SCM using mild steel casing with $42^{\circ}$ cone angle and $75 \mathrm{~mm} \mathrm{SoD}(2.5 \mathrm{x} \mathrm{CD})$. However, other configuration such as Aluminium at $120 \mathrm{~mm} \mathrm{SoD}(4 \times \mathrm{CD})$ also produced results. New SCM parameters were established for subsequent test by varying type of explosive, casing materials and SoD for results comparison to identify appropriate SCM parameters. Based on the entire test conducted, suitable small scale SCM parameters that can provide reliable laboratory scale hydrodynamic penetration blast test were established.

\subsection{Preparation of Plastic Explosive}

The density of the explosive has a direct bearing on its power, velocity and consistency of action. The PE should be prepared and compressed into the casing just prior to the experiment in a cool and dry environment to minimize heat exposure. Based on the less convincing results of the preliminary tests, a compressing mechanism was fabricated as shown in Figure 8. For all test using PE, the compressed PE average density is measured to be $1.474 \mathrm{~g} / \mathrm{cm}^{3}$.

\subsection{Hydrodynamic Penetration}

The blast tests for penetration of targets using the improved SCM were successfully conducted with positive results. Visual examinations shows the blast have produced significant penetrations. Evidence of the target surface at the jet entrance were being shoved aside by the penetrating jet and melting of the target plates with traces of molten copper on walls of the penetrated holes are shown in Figure 11a and 11b. These are two important criteria indicating that hypervelocity penetration of a shaped charge mechanism blast, facilitated by molten copper from the cone liner has taken place.

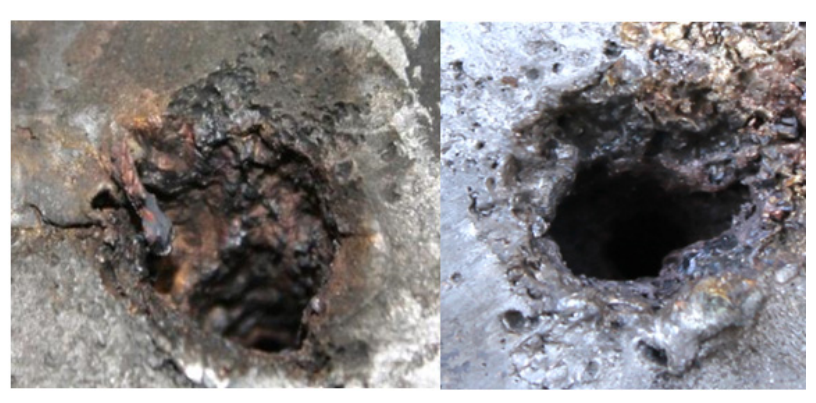

a. Jet Entrance

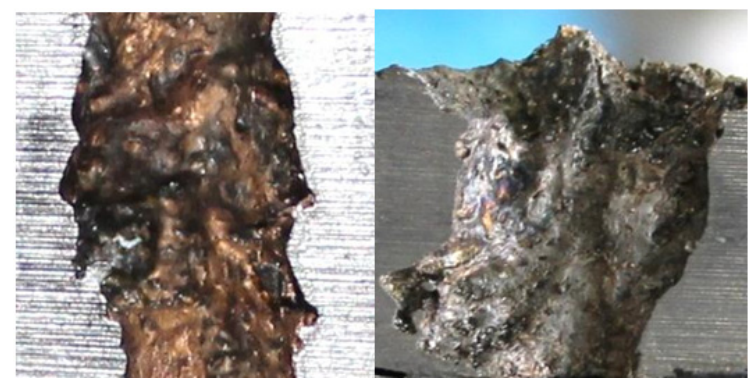

b. Cutway of Jet Penetration

Figure 11. Evidence of molten copper penetration that cause target plates to melt

\subsection{Copper Cone Parameters}

A copper cone with $42^{\circ}$ cone angle and $1.0 \mathrm{~mm}$ thickness is proven for better penetration results. Uneven distribution of cone collapse is evidence from melted copper which was dispersed on the target plate during blast thus affecting optimum penetration. Hence, cone fabrication need to be improved to ensure simultaneous and uniform collapse to maximised concentration of liquid metal jet for the penetration. New cones were fabricated (as shown in Figure 8) using copper-silver $(\mathrm{Cu}-\mathrm{Ag})$ brazing methods at the join followed by heat treatment below the brazing material melting temperature. For both the mild steel and Aluminium casing, the $1.0 \mathrm{~mm}$ copper cone liner produces better penetration than the $0.5 \mathrm{~mm}$ cone thickness.

\subsection{Casing Material}

These second test results are shown in Table 2 and 3 to verify casing material performances on the hydrodynamic penetration. The tests were intended to investigate the effects of casing materials on the penetration and not to compare between the military and commercial grade explosives. A Mild Steel, Aluminium and PVC casing were fabricated. A military grade PE was used in the first 4 test and a commercial grade EMULEX explosive were used in the second. Results from serial 3 of Table 2; for Aluminium casing with $1.0 \mathrm{~mm}$ cone liner shows residual molten copper that does not penetrate the target. This result as highlighted in Figure 12 may be caused by the ability of the Aluminium casing to hold enough pressure to push through the molten copper through the target plate. It is proven from both tests that the higher strength material makes better SCM casing thus produced better penetration results. 


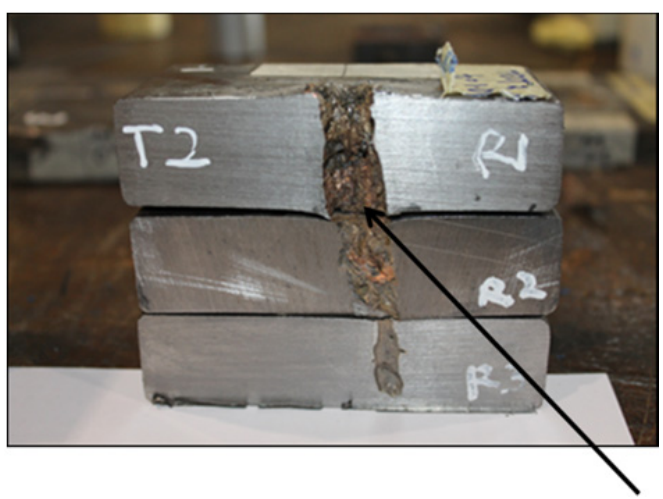

a. Location of hardened copper from molten copper jet

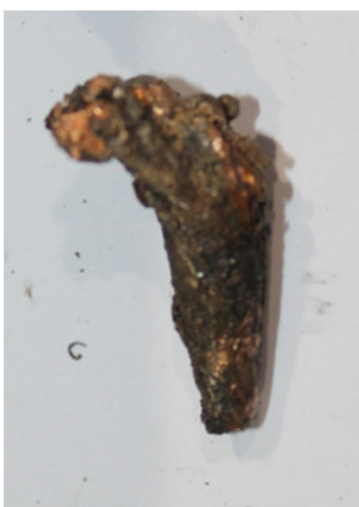

b. Harderned Copper Jet

Figure 12. Residue of molten copper

\subsection{Stand-Off Height}

Variable stand-off height was set during the $1^{\text {st }}$ preliminary test which later utilizes SoD of 2.0, 2.5 and 4.0 CD. All tests utilizing $2.5 \mathrm{CD}(75 \mathrm{~mm})$ standoff gave better results and were also proven by subsequent tests utilizing EMULEX explosive as shown in Table 3.

\subsection{Explosive Material}

Two types of explosive were used throughout these experiments that is Military Grade Explosive PE and a commercial grade explosive EMULEX. The Military Grade Explosive PE have resulted a significant hydrodynamic penetration. The penetration depths caused by EMULEX were significantly shallow due to the lower explosive VoD. Since EMULEX is easier to obtain, it may be used in future studies. However, some modifications in the SCM parameters may be required to obtain better penetration results.

\section{Conclusion}

A proof of good hypervelocity penetration results during the preliminary blast test using mild steel casing and a $1.0 \mathrm{~mm}$ cone thickness have resulted in an improved SCM parameters. All subsequent tests have been successful and visual examinations have proven that hypervelocity penetration of molten copper jet have taken place successfully. Examining data collected from all tests, a new set of SCM parameters for future test was concluded. For consistency of future test results, the SCM will be fabricated using dimensions as shown in Figure 6. A mild steel casing with $30 \mathrm{~mm}$ inner diameter and $4 \mathrm{~mm}$ thickness will be fabricated and fitted with copper cone liner of $1 \mathrm{~mm}$ thickness and $42^{\circ}$ cone angle. The SoD will be fixed at $2.5 \mathrm{CD}$ and fabricated using aluminium or PVC tube to hold the casing and cone liner. The overall dimensions of $50 \mathrm{~mm}$ in diameter and $200 \mathrm{~mm}$ in height is a suitable laboratory scale SCM size for future blast test to investigate a shaped charge hypervelocity penetration phenomena.

\section{References}

Baker, E. L., Pham, J., Madsen, T., Poulos., \& Fuchs, B. E. (2013). Shaped Charge Jet Characterization and Initiation Test Configuration for IM Threat Testing. Proceedings in the 12th Hypervelocity Impact Symposium, 2013, Procedia Engineering, 58, 58-6. http://dx.doi.org/10.1016/j.proeng.2013.05.009

Bolstad, J., Mandell, D., \& Mendius, P. W. (1992). Calculation of a Shaped Charge Jet Using MESA-2D and MESA- 3D Hydrodynamic Computer Codes. Los Alamos National Laboratory, University of California for the United States Department of Energy.

Bolton, O., Simke, L. R., Pagoria. P. F., \& Matzger, A. J. (2012). High Power Explosive with Good Sensitivity: A 2:1 Cocrystal of CL-20: HMX". Crystal Growth \& Design 12, American Chemical Society, 9, 4311-4314. Retrieved from http://pubs.acs.org/doi/pdf/10.1021/cg3010882

Bourne, B., Cowan, K. G., \& Curtis, J. P. (2001). Shaped charge warheads containing low melt energy metal liners. Proceedings of the 19th International Symposium of Ballistics 2001, Switzerland, 583-589. Retrieved from https://fas.org/sgp/othergov/doe/lanl/lib-www/la-pubs/00306772.pdf

Cooper, P. W. (1996). Explosives Engineering, New York: Wiley-VCH. 
Doig, A. (1998). Some metallurgical aspects of shaped charge liners. Journal of Battlefield Technology, 1(1), 1-3. Retrieved from http://cdn.preterhuman.net/texts/terrorism_and_pyrotechnics/explosives/Shaped_Charges_ Penetrators/Some_metalurgical_aspects_of_shaped_charge_liners.pdf

Fredrik, J., Vretblad, B., \& Sivertun, A. (2012). Shaped Charge Calculation Models For Explosives Ordnance Dispossal Operations. Journal of Military Studies, 3(1). Retrieved from http://ojs.tsv.fi/index.php/jms/article/view/7699/pdf

Globalsecurity.org (2011). Explosives-nitramines. Retrieved from http://www.globalsecurity.org/military/ systems/munitions/explosives-nitramines.htm

GlobalSecurity.org (2011). Shaped Charge. Retrieved from http://www.globalsecurity.org/military/systems /munitions/bullets2-shaped-charge.htm

Held, M. (2001). Liners for shaped charges. Journal of Battlefield Technology, 4(3), 1-7. Retrieved from http://cdn.preterhuman.net/texts/terrorism_and_pyrotechnics/explosives/Shaped_Charges_Penetrators/Liner s\%20for\%20Shaped\%20Charges\%20by\%20Manfred\%20Held\%20(2001).pdf

Kibe, S., \& Matsushima, M. (2002). Development of conical-shaped charge and hypervelocity impact experiments. National Aerospace Laboratory of Japan Research Progress 2001, 97-99. Retrieved from https://repository.exst.jaxa.jp/dspace/bitstream/a-is/26032/1/nalrp2002034.pdf

Ouye, N., Boeka, D., \& Hancock, S. (2007). Material Strength Effects on Shaped Charge Tip Velocities. 23rd International Symposium on Ballistics 2007, Tarragona, Spain. Retrieved from http://www.mater.upm.es/isb2007/Proceedings/PDF/Volume_1/Vol.I(24)WM18.pdf

Poole, C. (2005). Penetration of a Shaped Charge. (Doctoral Dissertation) Corpus Christi College, University of Oxford. Retrieved from http://eprints.maths.ox.ac.uk/211/1/poole.pdf

Saran, S., Ayisit, O., \& Yavuz, M. S. (2013). Experimental Investigations on Aluminium Shaped Charge Liners. The 12th Hypervelocity Impact Symposium 2013, Procedia Engineering, 58, 479-486. http://dx.doi.org/10.1016/j.proeng.2013.05.055

Tenaga, K. S. B. (2015). Technical Data Sheet, Emulex 700. Retrieved March 25, 2015, from http://www.tenagakimia.com/PDF/Updated\%20PDF/E700\%20General\%20_TDS_\%20_a_.pdf, 2015

U. S. Department of the Army Headquarters. (1990). Department of the Army Technical Manual-Military Explosives. Retrieved from http://militarynewbie.com/wp-content/uploads/2013/11/TM-9-1300-214Military-Explosives.pdf

Walters, W. (2007). Introduction to Shaped Charges. Weapons and Materials Research Directorate, Army Research Lab ARL-SR-150.

Walters, W., \& Zukas, J. A. (1989). Fundamentals of Shaped Charges. John Wiley and Sons, New York, NY1989.

\section{Copyrights}

Copyright for this article is retained by the author(s), with first publication rights granted to the journal.

This is an open-access article distributed under the terms and conditions of the Creative Commons Attribution license (http://creativecommons.org/licenses/by/3.0/). 